\title{
Pedagogy framework design in social networked-based learning: Focus on children with learning difficulties
}

\author{
Samira Sadat Sajadi* and Tariq M Khan
}

Brunel University London/Business school, London, UK

\section{H R O N I C L E}

Article history:

Received March 22014

Accepted 29 July 2014

Available online

August 22014

Keywords:

Constructivist Approach Pedagogy

Technology Enhanced Learning

Social Network

Attention Deficit Hyperactivity

Disorder

\begin{abstract}
A B S T R A C T
This paper presents an investigation on the theory of constructivism applicable for learners with learning difficulties, specifically learners with Attention Deficit Hyperactivity Disorder (ADHD). The primary objective of this paper is to determine whether a constructivist technology enhanced learning pedagogy could be used to help ADHD learners cope with their educational needs within a social-media learning environment. Preliminary work is stated here, in which we are seeking evidence to determine the viability of a constructivist approach for learners with ADHD. The novelty of this research lies in the proposals to support ADHD learners to overcome their weaknesses with appropriate pedagogically sound interventions. As a result, a framework has been designed to illuminate areas in which constructivist pedagogies require to address the limitations of ADHD learners. An analytical framework addressing the suitability of a constructivist learning for ADHD is developed from a combination of literature and expert advice from those involved in the education of learners with ADHD. This analytical framework is married to a new model of pedagogy, which the authors have derived from literature analysis. Future work will expand this model to develop a constructivist social network-based learning and eventually test it in specialist schools with ADHD learners.
\end{abstract}

\section{Introduction}

The use of social networks for educational purposes has recently drawn considerable attention from the research community, but little has been researched about the instructional design and pedagogical aspects of these new social learning 'systems.' It should be noted that the very benefits of a social approach to learning in which learners are able to communicate with peers as well as tutors to guide their learning, could also be one of its disadvantages where the quality of interactions can impact on the effectiveness and efficiency of learning. In particular, it remains to be seen whether social network based learning is a forum conducive to the needs and capabilities of every kind of learner, particularly those learners who would be considered to have special educational needs (e.g. ADHD, or ASD).

*Corresponding author.

E-mail addresses: samira.s.sajadi@gmail.com (S. S. Sajadi) 
One of the frequent neurobehavioral disorders in childhood is called Attention Deficit Hyperactivity Disorder (ADHD) that influences many learners worldwide (Swanson et al., 2003; Rogers et al., 2009; Jonsdottir et al., 2005). Since 1940s, different interpretations have been introduced with respect of ADHD: Postencephalitic Behavior Disorder (PBD) (Goldstein \& Goldstein, 1990); Brain Damage Syndrome (BDS) (Barkley, 2006; Birch, 1994; Berko et al., 1970); Minimal Brain Dysfunction (MBD) (Clements, 1971); Hyperkinetic Reaction of Childhood (HRC) (Weiss \& Hechtman, 1993); Attention Deficit Disorder (ADD) (Lerner et al., 1995) and finally Attention Deficit Hyperactivity Disorder (ADHD) (AAP, 2004).

Barkley defined ADHD as a "developmental disorder characterized by developmentally inappropriate degrees of inattention, over activity, and impulsivity. These often arise in early childhood; are relatively chronic in nature; and are not readily accounted for on the basis of gross neurological, sensory, language, or motor impairment, mental retardation, or severe emotional disturbance. These difficulties are typically associated with deficits in rule-governed behavior and in maintaining a consistent pattern of work performance over time (P. 47)" (Barkley, 2006). Today, education is playing a vital role in the society around the world. A great deal of research has been conducted aimed at developing educational tools for typically developing learners (TDLs). However, learners with learning difficulties or special educational needs (SEN) often find it difficult to learn in the same way as TDLs. Needs of the current research lied on: firstly, Lack of study on SEN, which have been concerned by researchers. Since, the focus of this study is on the special education needs particularly ADHD, how we can fit them into special education system? ADHD is very closely associated with education. Therefore, schools are the great challenge for them.

Having successful educational strategies are required at schools in order to enhance ADHDs' learning performance. Different teaching pedagogies have been conducted for children with special education needs. The research undertaken here is intended to develop a framework for pedagogy in social network-based learning in the context of special education, particularly learners with ADHD. In this respect, second needs of the research raised on lack of study on social networking. Therefore, we aimed to assemble significant pedagogy dimensions to facilitate learning in which they can benefit from. It is the objective of this paper to examine an introductory question: "To what extent is the theory of constructivism appropriate for learners with ADHD?" Consequently, this work may be applied to help lesson designers and schoolteachers determine whether aspects of constructivism are appropriate.

In sum, the current research has examined the links between constructivist learning approach from one side, and ADHD strength and weaknesses on the other side, to produce a model, which is intended to be used to identify the areas in which further investigation is needed to establish the value and worth of constructivist environment. The system will be designed based upon multimedia technology principles of (Moreno and Mayer, 1996) using social network-based learning environment.

\section{Literature Review}

This study intended to develop a framework for pedagogy in social network-based learning to support learners with ADHD. Hence, in the very beginning it is required to look into the theories behind learning. The term 'learning' refers to acquire new information, skills, behavior or adapting existing knowledge in the working memory (Anderson, 1996). In fact, human learning may categories in education and training arena. As a result, learning theories explain how learning occurs. Literature identifies a number of human learning theories that have had significant influences on education. However, our approach in this paper follows Jean Piaget and John Andersons' perspective on learning development model. 
Piaget's model investigated on the intellectual development of children's mind, which divided into 'assimilation' (absorbing materials form environment) and 'accommodation' (adapting their mental structures to cope with demands of environment). He has also focused on the personal development of knowledge and reconstruction concepts. As a result, constructivism originally was related to the nature of knowledge, as well as, the relation between brain and information. Constructivism is an educational theory developed by Jean Piaget (Piaget, 1954) in which learners recall their experience to develop meanings. Numerous studies defined constructivism as an educational 'learning theory' emphasizes on creating, constructing, inventing, and developing knowledge (Agda et al., 2011; Buyukduman \& Şirin, 2010; Kang et al., 2010; Payne et al., 2009; Tenenbaum et al., 2001; Reynolds, 2000; Keiny, 1994). Some other research examines constructivism as 'pure discovery' learning, and its core points include (Piaget, 1954; Vygotsky, 1998).

In fact, constructivism theory supports learners to develop their knowledge based on personal experiences, ideas, and learners' deep understanding of knowledge (Nie \& Lau, 2010). This means that learners should use their rich background of knowledge to create new concepts. However, in some cases learners' understanding is restricted which illustrates they might not have enough required knowledge. As a result, several cognitive educators have claimed criticisms on Piagets' constructivism theory. There are valid reasons to suggest that constructivist approach may not be applicable in some situations. Mayer claimed that not all educational techniques based on constructivist approach are effective (Mayer, 2004). He noted that guided discovery is efficient since it facilitates learners meeting two significant features for active learning: first, constructing accurate and relevant knowledge used to reproduce new incoming information and second, integrating new information with an appropriate knowledge base. Whilst, pure discovery might be inefficient when it fails to promote the second feature. Accordingly, Mayer's' viewpoint supports guided approach in a way to produce better learning outcomes. Studies of (Moreno, 2004; Tuovinen \& Sweller, 1999; Kirschner et al., 2006) noted that there should be a possibility of confusion with pure discovery. As a result, discovery learning shows less efficient in learning that could leads learner to misconceptions.

Since the focus of this research is on children with special educational needs, it is felt that constructivism theory of Piaget simply concerned to typically developing learners (TDLs) and did not taken SEN children into account. Therefore, our task here is clarifying to what extent the theory of constructivism is appropriate for SEN children. Several educational researches claimed that the constructivism learning theory provides both theoretical and practical basis on technology-based learning (Brandsford et al., 2000; Weigel \& van, 2002). Bates suggests that online learning has been seen as a valuable tool for adapting constructivist approaches in constructivism, which has a direct effect on the eLearning environment (Bates, 2005). This research has provided principles of constructivism in technology-based context.

\subsection{What is pedagogy?}

The term 'pedagogy' is a Greek word refers to the training and educating children. In education and academic arenas, pedagogy is an essential concept that has several interpretations. However, the main concern is used to refer to the quality of teaching methods and instrumental learning (Gore et al., 2004; Harper et al., 2004). Conole et al. (2004) claimed that pedagogy is a learning theory using for effective learning design. Sage and Baldwin (2010) defined pedagogy as "a communicative form of social learning and teaching that conveys knowledge applicable beyond a given social interaction". This illustrates the significant of social interaction for children to benefit learning. Moreover, Alexander described pedagogy for educational practice as introducing teaching methods and association (Alexander, 2001). 
Definitions above are all related to different perspectives of pedagogies, although all definitions are explaining the 'science of teaching' (Simon, 1999; Stevenson, 2008). However, the researcher defined pedagogy as a combination of significant aspects including: Delivery Medium, Design structure, Learning theories, Facilitation method, Knowledge construction, Context, Engagement mode, and feedback style. Based on the literature review, this study provided opportunities to suggest creative pedagogy definitions in respect of developing new teaching pedagogy appropriate for learners with ADHD.

\subsection{Social Network learning and pedagogy}

Today online social networking websites such as Facebook and MySpace have emerged as a new popular technology of education. In academic arenas, online social networking has been described as a learning practice environment for learners to support their collaborations and educational communications. Since rapid growth of Internet and technology has shown positive attitudes on users, we need to examine how social networks as a modern technology influences on education. Recently, learners as well as universities and colleges have used online social networks. The impact of social network on learning outcomes of university students has been investigated (Yu et al., 2010). Although several studies have been focused on social networking, little research has been done relevant to online social network learning in educational context (Roblyer et al., 2010). With this respect, we intended to observe pedagogy dimensions in social network-based learning in order to boost learning goals. There are a number of pedagogy elements in social networking which already are being used in different types of learning environment for instance, multimedia-based, Internetbased combining with gaming technologies and virtual worlds (Conole \& Culver, 2010).

\section{Scope of study}

The focus of our research is to examine the pedagogical elements of an instructional design for online social learning mediated through web 2.0 technologies. Further, our concern is with the ability for learners with special educational needs, such as ADHD, to take a full and active part in online learning with typically developing learners. Our objectives are to examine the design of learning experiences that could help special educational needs learners to overcome their inherent difficulties, as well as to develop their strengths. We aim to achieve this by decompiling the concept of a pedagogy from its usual imprecise and ambiguous usage as a catch all term to refer to "teaching methods', and place it on a firmer footing which will enable course designers to make informed decisions about the interventions and activities that need to be integrated in to a structured online social learning program. Thus our goal is to develop a new constructivist teaching pedagogy appropriate for learners with ADHD to help them better learn in online social 'educational' networks.

\section{Research Methods}

\subsection{Subject}

The current study included 55 participants both male and female recruited from ADHD support group communities, special education communities, psychologists, ADHD specialist and coaching, teachers, and parents located in the UK, USA, and Canada. The consent forms have been confirmed through the email. Their profiles including medical, academic, and educational performance were checked. All interviewees were entirely experienced in ADHD areas and their educational systems who had direct contacts with ADHD both adults and kids. Interestingly, some professional interviewees used to suffer from ADHD in the past; however, in today's condition several noticeable changes have been appeared in their circumstance. A brief overview of research objectives has been also delivered in order to their awareness from research they have involved. 


\subsection{Data Collection}

Data collections program were done over 6 weeks using online interviews and questionnaires. Semistructured interviews (Tashakkori \& Teddlie, 2003) have been employed consisting flexible and informal questions, which covered mutual communication. Group sessions of discussion, individual interviews, and individual online questionnaires with 55 participants helped us to provide in-depth information on both strength and weaknesses of ADHD children in one side, and their academic performance on the other side. The decision to concern predominantly qualitative data collections and analysis lied on the fact that this design is interested in insight, discovery, and interpretation rather than hypothesis testing to examine the reality in human lives (Merriam \& Sharan, 1998).

Online questionnaires were distributed to the subjects, ADHD support group communities, special education communities, psychologists, ADHD specialist and coaching, teachers, and parents, in an attempt to collect a primary data. Following that, online interviews were conducted on the same subjects to clarify unclear issues e.g. motor skills, IQ, academic performance, focusing and sustaining focus, effort, behavioral issues (monitoring self-action) and emotion, self-esteem as well as detailed on benefits of being ADHD. Furthermore, different special education and motivators list of ideas and resources to experiment and better performance of learning have been discussed. Group discussion were opened a great opportunity to share experiences and different perspective of teaching methods for SEN to improve their success of learning and cognitive skills.

\section{Findings and Discussion}

In this respect, our approach investigates firstly, different pedagogy dimensions as well as constructivism requirements. After reviewing the literature, we have developed the Table 1 below as a solution to cover the objectives of this study. Content of the table represents categories of pedagogies supported by the literature on different teaching strategies as well as lesson designers, which aimed to develop framework for pedagogy in technology-based learning.

\section{Table 1}

Pedagogy dimensions used in this study

\begin{tabular}{|c|c|c|}
\hline Requirements & Definitions & Examples \\
\hline Delivery Medium & Different delivery teaching content or learning materials & $\begin{array}{l}\text { Classroom-based, Internet-based, Multimedia / } \\
\text { Single Media learning, social Network-based }\end{array}$ \\
\hline Design Structure & $\begin{array}{l}\text { How to order and sequence the materials (lesson plans): } \\
\text { fixed, procedural approach (Linear)sequence or Open, } \\
\text { Networked structure (Non-Linear) }\end{array}$ & $\begin{array}{l}\text { Task-oriented lesson design, Hierachial learning } \\
\text { based on order of difficulties }\end{array}$ \\
\hline Learning Theory & How to manage and control learning & $\begin{array}{l}\text { Behaviorism, Constructivism, Instructionism, } \\
\text { Social Constructivism, Cognitivism, Multimedial } \\
\text { learning theory }\end{array}$ \\
\hline Facilitation Method & How to manage and control learning & Instructor-led, Socially-led, peer, Self-determined \\
\hline Engagement Mode & How a subject (e.g.IT users)interacts with an object & $\begin{array}{l}\text { Lecturer, Workshop, Project IT / Web-based } \\
\text { applications }\end{array}$ \\
\hline Assessment & Student Evaluation & $\begin{array}{l}\text { Assignments, Essay, Formative, summative, peer } \\
\text { feedback }\end{array}$ \\
\hline
\end{tabular}

\subsection{Pedagogy Dimensions}

Selection of appropriate pedagogy dimensions as a teaching strategy could be effective in order to motivate ADHD learners to overcome with their capabilities and limitations. Arrangement of suitable pedagogy could develop students' quality of learning. As a result of table below, we introduced two samples of pedagogy. Sample 1 shows a pedagogy designed for an active learner working on a specific task online with peers, within a formally set instructional program. Sample 2, by contrast, is a more informal environment, where the learner is observing passively other network user's activities 
and is not required to input. The two learners each use the social network for learning but they have different learning objectives. The course designer/instructor is able to identify what localized changes are needed to the pedagogy to achieve the most conducive setting for particular learning objectives. This approach provides greater control and justification for the design of the learning sessions, and allows the course designer to plan a series of sessions to achieve a set of learning objectives, which move through the program successively by modifying the pedagogy in specified ways.

In this respect, our task here is to develop support mechanism to allow learners to overcome with difficulties. In other words, we have to design the learning experiences wisely, which direct learners to use their strength to overcome weaknesses in order to reach learning goals. This is the rationale why this paper focuses on the design of new constructivist pedagogy help ADHDs to cope with their limitations of learning. Therefore, this research has pointed out to the other perspective of being ADHD, 'strengths and advantages of ADHD' as well.

\subsection{Discussion}

Although some studies have been conducted on special educations, little research has been focused on special educational strategies in social network-based learning environment appropriate for learners with ADHD. After applying online Interviews on the academic strength and weaknesses of ADHD, all impairments learned through literature has been established by interviewees. Cognitive impairments, low self-esteem, motor difficulties, intellectual development, academic impairments, social impairments, and emotional characteristics were the most problematic limitations that have stated by ADHD specialists. However, interestingly, we have discovered that most of their impairments could be act as advantages. Ability of hyper focus (hours of engagement, mental attention or concentration on a concept); rapid-fire mind (ability of brain process information at hyper speed); ability of multitasking (able to process multi tasks of interests simultaneously and effortlessly switch each one without breaking); idea generator (being creative and imaginative); high energy (blurting out answers); flexibility (ability to change as condition requires); and visual learner (Images, animations, graphs); were taking account into benefits of being ADHD. Studies of White and Shah noted that having ADHD might be boosted creativity (White and Shah, 2006). Positive attitude towards divergent thinking have been shown by ADHD to produce creative ideas. More important advantage on having impulsivity would be blurting out answers (Tymms and Merrel, 2011). This would require full engagement in an activity as well as shouting out answers at definite points.

Table 2

Pedagogy Samples

\begin{tabular}{ll}
\hline Pedagogical Elements & Sample 1 \\
\hline Delivery Medium & Social network \\
Design Structure & Network \\
Learning theory & Constructivism \\
Facilitation Method & Social-based \\
Engagement Mode & Task \\
Assessment & Peer-feedback \\
\hline Pedagogical Elements & Sample 2 \\
\hline Delivery Medium & Social network \\
Design Structure & Network \\
Learning theory & Constructivism \\
Facilitation Method & Social-based \\
Engagement Mode & Observation \\
Assessment & None \\
\hline
\end{tabular}


It is misleading that children with ADHD cannot focus on certain task, because it frequently happens. However, the difference is that they have ability to focus hours on things that do interest them e.g. video games, images, animations, and tables. Therefore, all these strength would be under the condition of things that passionately interested them. Hence, ADHDs need very high-quality learning environment and excellent teachers who can stimulate them. There are loads of tricks and routines that must be concerned by educational researchers. Therefore, through the interviews with ADHD specialist and experts beside literatures on different teaching strategies, decision been made by researchers on selection of appropriate teaching pedagogy. Because of this study, we investigating on social networking in a fun learning environment with mixed pedagogy dimensions explored above intended to boost their weaknesses in respect with better learning outcomes.

\section{Conclusion}

Special education is a term used to design particular instruction to meet ADHDs' requirements. For instance, teaching methods, learning tools and facilities, and special content might be essential in respect of improving learning performance. In fact, several psychological learning theories have been applied for special education (e.g. Multimedia learning theory by Richard Mayer (Mayer, 2001), cognitive load theory by Paivio, Chandler and Sweller (Paivio, 1986; Chandler \& Sweller, 1991), behaviorism Edward Thorndike and B. F. Skinner, and constructivism learning theory of Piaget (Skinner, 1935; Piaget, 1954). Therefore, special education teachers must develop individual teaching plan fit for a child with special education needs. In order for ADHD learners to benefit from constructivist approaches to learn, it is necessary to adopt suitable interventions that will support these learners in coping with their impairments as well as coping with demands of constructivism.

\section{Further Research}

This study has produced substantial contributions at the theoretical level. However, the model presented as working progress will be expanded through further literature and theoretical investigation in order to produce practical contributions. The model will be used to develop appropriate teaching pedagogy aimed at SEN learners to study over social network. The system will be evaluated through the analysis of typical analytics such as the time spend online, discussion group activity, chatting with ADHD coaches and specialists, and other social forms of learning engaged in by learners.

Additionally, practical contributions support SENCO department, academics (e.g. schools both mainstream and specialist), children with ADHD, and parents. The awareness of different teaching methods and interventions to enhance ADHDs' academic skills can influence SENCO, teachers, SEN learning assistant, and parents. This would results to adapt the new teaching pedagogy offered by researchers. We hope to discover positive patterns that indicate improved focus relevance and concentration by ADHD learners.

\section{Acknowledgement}

The authors would like to thank the anonymous referees for constructive comments on earlier version of this paper.

\section{References}

AAP, American Academy of Pediatrics. (2004). ADHD: A complete and authoritative guide. ELK Grove Village, I1: Author.

Anderson, J. R. (1996). ACT: A simple theory of complex cognition. American Psychologist, 51(4), 355. 
Aqda, M. F., Hamidi, F., \& Ghorbandordinejad, F. (2011). The impact of constructivist and cognitive distance instructional design on the learner's creativity. Procedia computer science, 3, 260-265.

Alexander, R. (2001). Still no pedagogy? Principe, Pragmatism and compliance in primary education. Cambridge Journal of Education, 34.

Baddeley, A. D. (1986). Working memory. Oxford University Press, Oxford.

Borras, L., Boucherie, M., Mohr, S., Lecomte, T., Perroud, N., \& Huguelet, P. (2009). Increasing self-esteem: efficacy of a group intervention for individuals with severe mental disorders. European psychiatry, 24(5), 307-316.

Bandura, A. (1982). Self-efficacy mechanism in human agency. American psychologist, 37(2), 122147.

Brook, U., \& Boaz, M. (2005). Attention deficit and hyperactivity disorder (ADHD) and learning disabilities (LD): adolescents perspective. Patient Education and Counseling, 58(2), 187-191.

Barkley, R. A. (2005). Attention-deficit hyperactivity disorder: A handbook for diagnosis and treatment (Vol. 1). Guilford Press.

Bates, A. (2005). Technology, E-learning and Distance Education. $2^{\text {nd }}$ Ed., Routledge Falmer Studies.

Birch (1964). Brain damage in children- The biological and social aspects. The Williams and Wilkins Company.

Berko, F., Berko, M., \& Thompson, S. (1970). Management of brain damaged children- A parent's and teacher's guide. Springfield, IL: Bannerstone House.

Bransford, J. D., Brown, A. L., \& Cocking, R. R. (1999). How people learn: Brain, mind, experience, and school. National Academy Press.

Büyükduman, İ., \& Şirin, S. (2010). Learning portfolio (LP) to enhance constructivism and student autonomy. Procedia-Social and Behavioral Sciences, 3, 55-61.

Chandler, P., \& Sweller, J. (1991). Cognitive load theory and the format of instruction. Cognition and Instruction, 9, 293-332.

Clements, S. (1971). Nomenclature. In: L. Reginald (ED.), problem and issues in the education of exceptional children. Boston, MA: Houghton Mifflin Company.

Conole, G., Dyke, M., Oliver, M., \& Seale, J. (2004). Mapping pedagogy and tools for effective learning design. Computers \& Education, 43(1), 17-33.

Conole, G., \& Culver, J. (2010). The design of Cloudworks: Applying social networking practice to foster the exchange of learning and teaching ideas and designs. Computers \& Education, 54(3), 679-692.

Goldstein, S., \& Goldstein, M. (1990). Managing attention disorders in children: A guide for practitioners. John Wiley \& Sons.

Gore, J. M., Griffiths, T., \& Ladwig, J. G. (2004). Towards better teaching: Productive pedagogy as a framework for teacher education. Teaching and teacher education, 20(4), 375-387.

Harper, K. C., Chen, K., \& Yen, D. C. (2004). Distance learning, virtual classrooms, and teaching pedagogy in the Internet environment. Technology in Society, 26(4), 585-598.

Holt-Reynolds, D. (2000). What does the teacher do?: Constructivist pedagogies and prospective teachers' beliefs about the role of a teacher. Teaching and Teacher Education, 16(1), 21-32.

Jonsdottir, S., Bouma, A., Sergant, J. A., \& Scherder, E. J.A. (2005). The impact of specific language impairment on working memory in learners with ADHD combined subtype. Archives of Clinical Neuropsychology, 20, 443-456.

Kang, L. O., Brian, S., \& Ricca, B. (2010). Constructivism in pharmacy school. Currents in Pharmacy Teaching and Learning, 2(2), 126-130.

Kirschner, P. A., Sweller, J., \& Clark, R. E. (2006). Why minimal guidance during instruction does not work: An analysis of the failure of constructivist, discovery, problem-based, experiential, and inquiry-based teaching. Educational psychologist, 41(2), 75-86.

Keiny, S. (1994). Constructivism and teachers' professional development.Teaching and Teacher Education, 10(2), 157-167. 
Lerner, J., Lowenstein, B., \& Lerner, S. (1995). Attention deficit disorders: Assessment and teaching. Pacific Grove, CA: Brooks/Cole.

Mayer, R. E. (2001). Multimedia learning. New York: Cambridge University Press.

Mayer, R. E. (2004). Should there be a three-strikes rule against pure discovery learning?. American Psychologist, 59(1), 14-19.

Merriam, S. B. (2014). Qualitative research: A guide to design and implementation. John Wiley \& Sons.

Moreno, R. (2004). Decreasing cognitive load in novice students: Effects of exploratory versus corrective feedback in discovery-based multimedia.

Moreno, R., \& Mayer, R. E. (1999). Cognitive principles of multimedia learning: The role of modality and contiguity. Journal of educational psychology, 91(2), 358.

Nie, Y., \& Lau, S. (2010). Differential relations of constructivist and didactic instruction to students' cognition, motivation, and achievement. Learning and Instruction, 20(5), 411-423.

Payne, A. M., Stephenson, J. E., Morris, W. B., Tempest, H. G., Mileham, A., \& Griffin, D. K. (2009). The use of an e-learning constructivist solution in workplace learning. International Journal of Industrial Ergonomics, 39(3), 548-553.

Paivio, A. (1986). Mental representations: A dual coding approach. New York, USA: Oxford University Press. Computer and Education.

Piaget, J. (1981). Intelligence and affectivity: Their relationship during child development.(Trans \& Ed TA Brown \& CE Kaegi). Annual Reviews.

Roblyer, M. D., McDaniel, M., Webb, M., Herman, J., \& Witty, J. V. (2010). Findings on Facebook in higher education: A comparison of college faculty and student uses and perceptions of social networking sites. The Internet and Higher Education, 13(3), 134-140.

Rogers, M. A., Wiener, J., Marton, I., \& Tannock, R. (2009). Parental involvement in children's learning: Comparing parents of children with and without Attention-Deficit/Hyperactivity Disorder (ADHD). Journal of school psychology, 47(3), 167-185.

Sage, K. D., \& Baldwin, D. (2010). Social gating and pedagogy: Mechanisms for learning and implications for robotics. Neural Networks, 23(8), 1091-1098.

Simon, B. (1999). Why no pedagogy in England? Abridged version. Learners and pedagogy. London: Paul Chapman in association with The Open University.

Skinner, B. F. (1935). The generic nature of the concepts of stimulus and response. The Journal of General Psychology, 12(1), 40-65.

Stevenson, I. (2008). Tool, tutor, environment or resource: Exploring metaphors for digital technology and pedagogy using activity theory. Computers \& Education, 51(2), 836-853.

Swanson, J. M., Reschly, D., Fine, A. H., Kotkin, R. A., Wigal, T., \& Simpson, S. (2003). Traditional and innovative assessment of children with Attention deficit hyperactivity disorder and learning disorders. Therapists guide to learning and attention disorders, 43-86.

Tashakkori, A., \& Teddlie, C. (Eds.). (2010). Sage handbook of mixed methods in social \& behavioral research. Sage.

Tenenbaum, G., Naidu, S., Jegede, O., \& Austin, J. (2001). Constructivist pedagogy in conventional on-campus and distance learning practice: An exploratory investigation. Learning and instruction, 11(2), 87-111.

Tuovinen, J. E., \& Sweller, J. (1999). A comparison of cognitive load associated with discovery learning and worked examples. Journal of educational psychology, 91(2), 334-341.

Tymms, P., \& Merrell, C. (2011). ADHD and academic attainment: Is there an advantage in impulsivity?. Learning and individual differences, 21(6), 753-758.

Vygotsky, L. S. (1980). Mind in society: The development of higher psychological processes. Harvard university press.

Weiss, G., \& Hechtman, L. (1993). Hyperactivity children grown up. New York: Guildford Press.

Weigel, V. B. (2002). Deep Learning for a Digital Age: Technology's Untapped Potential To Enrich Higher Education. Jossey-Bass, 989 Market Street, San Francisco, CA 94103-1741. 
2154

White, H. A., Shah, P. (2006). Uninhabited Imaginations: Creativity in adults with AttentionDeficit/Hyperactivity Disorder. Personality and Individual Differences, 40, 1121-1131.

Yu, A. Y., Tian, S. W., Vogel, D., \& Chi-Wai Kwok, R. (2010). Can learning be virtually boosted? An investigation of online social networking impacts.Computers \& Education, 55(4), 1494-1503. 